\title{
WHO must remain a strong global health leader post Ebola
}

The 2014 Ebola outbreak in West Africa has demonstrated again the urgent need for strong leadership and coordination in responding to global health challenges. As members of the global health scholarly community, we the undersigned call upon all Member States of the World Health Organization (WHO) to recommit themselves to strengthening global outbreak alert and response by sustainably investing in the WHO, its departments and personnel.

As members of the WHO secretariat have admitted, mistakes were made in how the organization initially responded to the 2014 Ebola outbreak.

Ahead of the 68th World Health Assembly in May 2015, the temptation will be to point fingers and use the extreme case of Ebola to justify further erosion of the WHO. The temptation may also be to divert voluntary contributions to other institutions. We firmly believe that any such measures must be approached with extreme care.

In international forums, a proposal is being discussed to establish a new 'first responder' United Nations agency. It has been suggested the proposed agency will provide emergency operational assistance in humanitarian crises by rapidly deploying trained personnel, equipment and supplies.

While an enhanced rapid response would be beneficial, a new agency would be subject to the same vagaries of institutional funding and member state interests in delivering its mandate.

Even more importantly, these are functions that the WHO already fulfils via the Global Outbreak Alert and Response Network (GOARN), which maintains a roster of experts that can be deployed to assist in humanitarian disasters. The resources to create an entirely new agency would therefore be better served by strengthening the WHO's emergency response division rather than duplicating existing functions. Resources could also be more effectively used to help member states implement the International Health Regulations (2005) via health system strengthening.

An independent investigation of the WHO's handling of the 2014 Ebola outbreak is both appropriate and warranted. The investigation should focus on the structural and procedural elements of institutional practice; consider how recent funding cuts affected the WHO's ability to respond; and identify pathways to sustainable funding of the institution.

The WHO can provide global health leadership that is technically informed and representative. The organization remains a fundamental element of global health governance, and provides an indispensible service as the lead technical agency in global health. While mistakes have been made, rather than engage in the further dismantling of the WHO we call on all Member States and the international community to give the organization the resources it needs to serve its members and the populations they represent.

Authors:

Adam Kamradt-Scott, University of Sydney 
Sophie Harman, Queen Mary University of London

Joao Nunes, University of York

Anne Roemer-Mahler, University of Sussex

Clare Wenham, London School of Hygiene and Tropical Medicine

\section{Additional signatories:}

The People's Health Movement

Kenneth Abbott, Jack E Brown Professor of Law, Arizona State University

Emma-Louise Anderson, University of Leeds

Lesley Barclay AO, Professor and Director, University Centre for Rural Health

Amy Barnes, University of Sheffield

Peng Bi, Professor, University of Adelaide

Colin Binns, Distinguished Professor of Public Health, Curtin University

Thomas Briese, Associate Professor of Epidemiology, Columbia University

Dorothy Broom, Professor Emerita, Australian National University

Lai-Ha Chan, University of Technology, Sydney

Simon Chapman AO, Professor, University of Sydney

Karen Charlton, Associate Professor, University of Wollongong

Catherine Cherry, Physician and Associate Professor, Burnet Institute

Rufus Clarke, Honorary Clinical Professor, Macquarie University

Benjamin Cowie, Associate Professor, University of Melbourne

Sara Davies, Queensland University of Technology

Layla Distler, Philipps-Universität Marburg

Judith Dwyer, Professor, Flinders University

Julian Eckl, University of Hamburg, Germany

Paul Effler, Professor, University of Western Australia

Christian Enemark, Aberystwyth University 
Delia Enria, Instituto Nacional de Enfermedades Virales Humanas

Colleen Fisher, Professor, University of Western Australia

Dale Fisher, Professor of Medicine, National University of Singapore

John Ferguson, Physician and Professor, Hunter New England Health

Anna George, Adjunct Professor, Murdoch University

Lyn Gilbert, Professor, University of Sydney

Shri Rose Govindaraj, Assistant Professor, Pondicherry University

Erin Graham, Drexel University

Shannon Guillot-Wright, University of Texas Medical Branch

John Hall, Associate Professor of Public Health, University of Newcastle

Lori Hanson, Associate Professor, University of Saskatchewan

Tine Hanrieder, WZB Berlin Social Science Center

Peter Hill, Associate Professor of Global Health Systems, University of Queensland

Grant Hill-Cawthorne, University of Sydney

Rebecca Hester, Assistant Professor, University of Texas Medical Branch

James Hyde, Professor of Public Health Policy, Deakin University

Rachel Irwin, Karolinska Institutet

Erica James, Associate Professor of Public Health, University of Newcastle

Josep M Jansa, European Center for Disease Prevention and Control

Laksiri Jayasuriya AM, Emeritus Professor, University of Western Australia

Jayantha Jayman, Assistant Professor of Global Political Economy, St Lawrence University

Guillaume Jeannerod, Epidemiology and IT Systems for Public Health

Cheryl Jones, Professor of Paediatrics, University of Sydney

Madhav Joshi, Assistant Professor, University of Notre Dame

Adele Langlois, University of Lincoln 
James LeDuc, Professor, University of Texas Medical Branch

Pak Lee, University of Kent

David Legge, Scholar Emeritus, La Trobe University

Poh Lian Lim, Professor, MD, Tan Tock Seng Hospital, Singapore

W. Ian Lipkin, John Snow Professor, MD, Columbia University

Linda Mans, HealthWorkers4all

Ben Marais, Associate Professor, University of Sydney

Gavin Macgregor-Skinner, Pennsylvania State University

John Mackenzie AO, Research Associate and Professor of Tropical Infectious Diseases, Curtin University

Bruce Maycock, Professor, Curtin University

John McBride, Professor, James Cook University

Colin McInnes, UNESCO Professor of HIV/AIDS and Health Security in Africa, Aberystwyth University

Michael Moore, CEO, Public Health Association of Australia

Chris Paul, Duke University

Valerie Percival, Carleton University

Marian Pitts, Emeritus Professor, La Trobe University

Babatunde Olowokure, Caribbean Public Health Agency

Stephen Rogerson, Professor of Medicine, University of Melbourne

Angela Rose, University of West Indies

Jyotika Saksena, University of Indianapolis

Thomas Schwarz, Medicus Mundi International Network

Linda Selvey, Associate Professor, Curtin University

Hani Serag, People's Health Movement

Tania Sorrell AM, Physician and Professor, University of Sydney 
W John Spicer, Physician and Professor, Monash University

Preslava Stoeva, London School of Hygiene and Tropical Medicine

Hugh R Taylor AC, Laureate Professor, University of Melbourne

Nicholas Thomas, Associate Professor, City University of Hong Kong

Michael Toole AM, Deputy Director and Professor, Burnet Institute

Sian Tsuei, University of British Columbia.

Mark Turner, University of Manchester

Mary Upton, Open University

Maria Van Kerkhove, Imperial College London

Ian W Webster, Physician and Emeritus Professor, University of New South Wales

Sungwon Yoon, University of Hong Kong

Jeremy Youde, Associate Professor, University of Minnesota Duluth

Anthony Zwi, Professor of Global Health and Development, University of New South Wales 